\title{
The Socially Situated Dynamics of Children's Learning Processes in Classrooms: What Do We Learn from a Complex Dynamic Systems Approach?
}

\author{
HENDERIEN STEENBEEK, SABINE VAN VONDEL, \& PAUL VAN GEERT \\ University of Groningen (The Netherlands)
}

\begin{abstract}
This article concentrates on the question what kind of model - conceptual and statistical -can serve as a good working model for the study of learning and teaching processes qua processes. We claim that a good way of answering this question is to begin by observing a teaching and learning process as, where, and when it occurs. In addition, a conceptual model of intertwined learning-teaching processes is discussed, and dynamic modeling as an approach to theory formation about teaching-learning processes. The focus lies on the evolution term, the timescale of interaction processes, state space as a perspective on teacher-student interaction dynamics, and the principle of agency. Finally, an empirical approach to studying teaching-learning processes is illustrated by means of a case study, focusing on the use of cluster analyses techniques. In the Conclusion and Discussion section, further perspectives on theory building and empirical research are discussed.
\end{abstract}

\section{Introduction}

How do intentionally regulated, interactional learning processes develop over time? How can a complexity approach help in understanding these processes? For instance, if children learn about math or science in the classroom setting, the learning is embedded in a complex process of interaction between the children, teachers and the materials they are working with. Can the contributions of each of these components be estimated by disentangling their influence from the complex whole of influences on learning? They can, in principle, if this complex whole of interactions can be treated as a basically linear system, in which the contributions of each of the 
components add up. The belief that this can indeed be done, forms the basis of the dominant approach in the behavioral and learning sciences. For instance, the explained variance approach tries to discover how much variance in a particular variable - such as learning effect or performance levels of any particular sample of students - can be explained by, that is corresponds with, the variance in an independent variable (e.g., professional quality of a teacher). Techniques of explained variance form the workhorses of the overwhelming majority of behavioral and learning studies, which have indeed succeeded in disentangling the influence of an arbitrarily large amount of variables on learning outcomes.

Do the successes of these techniques indeed imply that the process of learning is, in the end, a linear system, which, although it is indeed very complicated, can be successfully dismantled in the form of a series of independent variables?

One thing that the standard studies have demonstrated time and again is that it is possible to transform the data on learning processes into a basically linear form. This transformation takes place by adding the data about individual cases over a - preferably very big - sample of such cases, such as individual classes, individual students and individual teachers. That is, it can be done by employing these data as information about differences and similarities between the cases. For instance, by collecting the data on a great many school classes, one obtains a performance score $a$ for student $\mathrm{A}$, a score $b$ for a student $\mathrm{B}$, a score $c$ for a student $\mathrm{C}$, and so forth, a treatment score $X$ for students $A$ and $B$, a treatment score $Y$ for students $C$ and $D$ and so forth. Or, to put it differently, one can transform a process, which is basically a sequence of connections between an event and the following one, and one following that one into a linear system by turning it into a collection of independent connections between an event (e.g. a score) and another one (e.g. a treatment). However, the word "connection" means something very different if it is treated in the context of a temporal connection in a particular process, where a preceding event causally or conditionally connects to the following event, than if it is treated in the context of connections between independent cases. In the latter context, the concept of connection applies to the differences and similarities between the cases on a particular variable, such as a level of school performance of a great many individual students. The current work on the so-called ergodicity principle (Molenaar, 2004; Molenaar \& Campbell, 2009) has demonstrated that there are no reasons to believe that models of such between-case connections, e.g. in the form of regression models, can serve as models of within-case connections, i.e., of causal and conditional connections in a stream of learning and teaching events in a particular classroom (Van Geert, 2014). Unfortunately, the belief that they can in fact do so is very widespread in the current practice of teaching and learning research, in spite of the fact that the still relatively scarce empirical tests of this belief convincingly show that it is not warranted (Molenaar \& Campbell, 2009; Toonen et al., 2016).

Earlier in this introduction, we asked ourselves whether the successes of group-based statistical techniques indeed imply that the process of learning is, in the end, a linear system, whether the variance in the quality of teaching and learning can be explained by the contribution of independent variables. Our answer is that if the individual and process nature is taken out of the data by aggregating them in the form of inter-individual variability, the resulting models will indeed describe a basically linear system that statistically explains the distribution of variables across a population, but that fails to describe the individual processes. 
If these standard models, based on statistical associations between independent cases cannot serve as a model of the processes that gave rise to those statistical associations across populations (or representative samples), we should ask ourselves what kind of model conceptual and statistical - can serve as a good working model for the study of learning and teaching processes qua processes? This article concentrates on this question, and answers it by focusing on the casus of science learning in primary schools. That is, we think that a good way of answering this question is to begin by observing a teaching and learning process as, where, and when it occurs.

\section{Science learning in primary school: an example of intertwined processes}

The following example originates from our study of science learning in primary school in the context of an intervention aimed at the teacher's pedagogical practices such as the use of questions that elicit students' scientific understanding and engagement (van Vondel, Steenbeek, Van Dijk, \& Van Geert, 2016; 2017a; 2017b). This illustration comprises a short transcript of a teacher-student interaction during a science lesson. In this transcript both the teacher's utterances and the student's utterances were coded, such as the teacher's use of didactic strategies (e.g. the number and level of openness of teacher questions), and the level of understanding in the student's utterances (or: whether there was reasoning or not). This was done per utterance using sequence analysis; both on the micro-level of one interaction, and on the macro-level over several lessons over the course of the intervention. The illustration aims to show that on the micro-level of one short interaction during science lesson the pupil builds up understanding, and uses higher levels of reasoning than she did in the beginning of the interaction. In other words: the interaction dynamics gives a context for her building up her knowledge and understanding during this micro-interaction-event.

In an experiment in a group of 9-10 year old students (upper grade/ regular education), two piles with books of equal height are placed next to each other (in between: 15 centimeter; 5.9 inch), on top of both lies a paper sheet. The teachers ask what will happen when the student blows underneath the paper sheet. The student replies: 'I have no idea'. The teacher then asks: 'what do you think will happen with the paper sheet?'. The student formulates her hypothesis: 'the paper sheet will fly away'. She starts blowing underneath the paper sheet and notices to her surprise that the paper sheet collapses instead of flying away.

The teacher continues: 'What do you think causes the paper sheet to collapse instead of fly away, when you blow?'. The pupil answers: 'the blowing causes the air to move, which then causes 'holes' in the air, which makes the weight of the air above the paper sheet being heavier than the weight below the paper sheet'. The pupil thus explains what she has just seen, adding extra information about aspects of the experiment that she could not directly observe. She describes invisible elements, such as the air, holes in the air, and shows that she understands now that a change (blowing underneath the paper sheet) causes the whole system to change (above the paper sheet the air is suddenly heavier in comparison with the air underneath the paper sheet), which was not the case before she started blowing. She uses a rather high level of reasoning (as measured with Fischer's skill theory levels: Fischer, 1980; Meindertsma et al., 2012; Van der Steen, 2014). This transcript is one of the interaction fragments that were (video-) 
observed. For more information about the coding procedure etc., we refer to Van Vondel, Steenbeek, van Dijk, Van Geert, 2017a, 2017b).

The goal of the current project was to improve science and technology education in the upper grades of elementary education by supporting teachers with theory, practical tools, and immediate video feedback by means of the intervention Video Feedback Coaching for upper grade teachers. More specifically, this pedagogical-didactic intervention was developed to stimulate change in teacher-student interactions, i.e., changing the discourse from mostly teacher-centered into a more stimulating student-centered discourse (Wetzels, et al., 2016). By doing so, teachers enhance the quality of students' scientific reasoning skills by establishing a series of inspiring teachable science moments (Bentley, 1995; Hyun \& Marshall, 2003).

\section{Towards a Conceptual Model of Intertwined Learning-Teaching Processes: Teaching-learning is a Form of Interaction}

Let us take a closer look at the example of a fragment of a science activity in the class, as described in the above section. The first - and far from surprising - observation is that learning as well as teaching takes place in interaction between the participants (DePaepe, de Corte, \& Verschaffel, 2006; Fogel, 2009; Sorsana, 2008; Vosniadou, 2007). What a particular child is actually doing at a particular moment, i.e., her level of reasoning, or what a teacher is doing for that matter, i.e., her use of questions, is always the result of an intertwining person-context dynamics. What a particular child is doing enduring each time step in this observed fragment focusing on the activity, looking away, asking a question, giving an answer, manipulating materials, or addressing another child, forms a connected chain of events. This chain of events is continuously interfering with other chains of events, namely the activities of other children, of the teacher, and of what happens with the materials used in this science activity. That is, we are studying deeply intertwined chains of events.

\section{Processes as Iterative Sequences of Intertwined Events}

If children are busy manipulating a particular set of materials to perform an experiment, each manipulation can be defined as an event (e.g., placing two piles of books, placing paper on top of the two books, blowing underneath the paper, visually following the paper to collapse). In a sequence of such experiments, e.g. with different objects placed on the top of the two books, each experiment can be defined as an event. That is, these intertwined events form an embedded pattern, with the short-term events embedded in a pattern of longer-term events, or, to put it differently, it forms a structure of embedded timescales.

A chain of events on the same timescale forms an iterative process. By "iterative" we mean that the next event originates from a limited and repetitive set of principles acting on the preceding event. They can be simple interaction principles, such as the principle of the student giving an answer to what he perceives as a question, giving a teacher reaction to what is perceived as an answer and so forth. Events typically differ in the form and extent to which such principles are applied over different contexts and with different participants (for instance, the teacher asking a question to young primary school students immediately triggers much more 
and much more enthusiastic answers, than a question asked by a typical university lecturer addressing a big audience of young adult students).

\section{Timescales and Their Proper Dynamics}

Conditional relationships not only occur between events at a particular time scale, but also between events at different time scales. A sequence of experiences on a microgenetic timescale, e.g. during a particular science activity, has an effect on the sequence of events on a more macrogenetic timescale, e.g. a sequence of consecutive science lessons. This is a typical learning effect (learning about science principles and possible explanations, building up expectations about questions typically asked by the teacher, or explanations typically given by the students). On the other hand, a sequence of events on the macrogenetic timescale of consecutive science lessons, has an effect on the sequence of events that take place within a particular science lesson: changes in knowledge and expectation will have an effect on the nature of answers given, on the level of enthusiasm and engagement during the lesson and so forth.

Chains of events on different timescales (e.g. microgenetic versus macrogenetic) are characterized by their own, typical dynamics. The dynamics governing event sequences on the microgenetic level are typically based on social interaction "rules", such as the teacher perceiving a student's action in terms of a particular level of understanding, perceiving that understanding or lack thereof as a particular educational opportunity, acting on that perception by asking an open question; the student's perception of a teacher's question as an invitation to give a particular type of answer, giving that answer immediately, the teacher's then waiting for a response, or direct claim elaborating on the answer given by the student, and so forth. The dynamics governing event sequences on the macrogenetic level of consecutive lessons is governed by the teacher's following a particular lesson protocol (the curriculum), by the cumulative as well as nonlinear effects of experiences in terms of building up knowledge, expectations and attitudes, in the form of a teacher's knowledge, expectations and attitudes about the progress made by his students, or in the form of a student's knowledge about a particular science domain, expectations about the sort of questions asked by the teacher, and changes in terms of engagement and enthusiasm for the type of activity taking place during the lessons.

\section{Perspectives on Complex Processes}

Given the complexity of this intertwined pattern of activities of teachers and students, it is possible - and in many cases also advisable - to view a particular teaching-learning process from the perspective of one of the participants. For instance, one can take the perspective of the teacher, or the perspective of one of the students in the class, and study the sequence of events associated with this particular participant. However, given the intertwined character of the processes, the selection of one of the participants indeed amounts to taking a particular perspective on the complex intertwined whole. This is very different from making a straightforward reduction of the complex whole, i.e., by reducing it to what happens with one of the participants (either the teacher, or a particular student, or the group of students taken as a unity of action). For instance, we can take the perspective of the teacher, and focus on the nature 
of the questions he or she is asking, but the sequence of such questions on different timescales cannot be understood without taking the answers of the students into account. In a similar vein, one can take the answers, or the engagement or enthusiasm of the students, as one's perspective on the intertwined and complex process, but the sequence of such answers or expressions of engagement cannot be understood without taking the teacher's questions and explanations into account.

If one takes a particular participant as perspective on the entire process, that participant's chain of actions forms the focus, and the chain of events taking place in the other participants and in the materials manipulated during the activity, forms the context. It is clear that on the level of this process study, the context cannot be treated as an independent variable, because of the chain of events constituting the context is deeply intertwined with the chain of events constituting the focus. In this way, the activities of the student co-create its context, and the context co-creates the student's activities. Take for instance the student $S$ as the focus, and the teacher $\mathrm{T}$ as the context. This process of co-creation of focus and context takes place on the timescale of the activity itself: a question (T) triggers an answer (S), an answer (S) might trigger an explanation ( $\mathrm{T}$ and/or $\mathrm{S}$ ), an explanation ( $\mathrm{T}$ and/or $\mathrm{S}$ ) might trigger a feeling of certainty or uncertainty ((T and/or $S)$, certainty or uncertainty might trigger a question (T or $S$ ), and so forth. It is clear that if the researcher breaks the temporal sequentiality of T-S events and creates a database of separate S-T associations, in one particular class or in many such classes, the researcher end up with a database in which the context $(\mathrm{T})$ can indeed be treated as an independent variable, and S as the dependent variable, the variance of which can be "explained" by the variance in the context. However, what is explained here is a collection of statistically independent associations, whereas it should explain the sequence of conditionally coupled events. Hence, in order to explain the data, the sequence of events should be treated as a sequence. However trivial this recommendation sounds, it requires a rather dramatic change in the habitual research designs and methods.

In addition to making empirical and methodological recommendations on the basis of the expected process properties, one should also think about the theoretical recommendations following from this reflection on the defining features of teaching-learning processes. If such processes are iterative, intertwined events of sequences taking place on various interconnected timescales, one should build theories and models in which these properties are explicitly accounted for. In our view, the best possible way to implement these properties in a theoretical model is to build a dynamic model of the process, which can be formulated in the form of a mathematical and/or simulation model. In the next section, we will give an example of such a model, based on our previous research.

\section{Dynamic Modeling as an Approach to Theory Formation about Teaching-Learning Processes Explaining Dynamics through Its Evolution Term}

If a teaching-learning process consists of intertwined sequences of events (each sequence corresponding with a participant or participating component in the process), then a teaching-learning process theory must be able to "predict" such intertwined sequences of events, given a particular starting point of the process. That is to say, it must be able to answer 
the question "if this particular state is the starting point of a process, what will the resulting process be like?" The answer takes the form of a description of sequences of intertwined events. The underlying explanation of the sequence relies on an explicit principle of change, that is, an evolution term, which must be so that, given any event in the sequence, the next event in the sequence logically follows by applying that principle of change to the properties of the given event. In the case of social interaction and learning, this principle of change will most likely amount to a small set of such principles, describing for instance which kind of action will follow the preceding action or actions. An example of such a principle is "do what the other person does", and if both participants in an interaction process follow that particular principle, the process will take the form of a sequence of highly similar actions. Although this principle sounds rather simple, if not stupid, it actually does play a role in interaction processes, for instance during collaborative play of two children (Steenbeek, van der Aalsvoort \& van Geert, 2014)

Another, more specific, example of a principle that describes the changes in an educational event sequence is "assign a task to the other person that is slightly above his or her current capabilities". This principle will only lead to an ongoing event sequence, if the participant addressed in the principle follows another principle, which is "do what the other participant instructs you to do". An additional principle may be "if you can't to do what the other participant instructs you to do, withdraw from the interaction" (or: "ask that other participant for help"). Applying these and comparable principles to some starting point of an educational interaction (e.g. the start of a particular lesson), will result in a description of intertwined sequences of events that are typical of successful or unsuccessful educational scaffolding processes (Steenbeek \& Van Geert, 2013; Ensing, van der Aalsvoort, Van Geert \& Voet, 2014).

In dynamic systems terminology, these principles are called the system's evolution rules. That is, they describe the principles by which one state of the system evolves into another state (and from that state into yet another state etc.) over the course of time. In a mathematical model, for instance a growth model, the evolution term takes the form of a mathematical operation or set of operations, but in the simulation model, such as agent models, the evolution term takes the form of action rules.

\section{Explaining Interaction Dynamics by the Principle of Agency}

We have argued elsewhere, that in order to dynamically model social interaction processes, including teaching-learning processes, the system's evolution rules should be based on the concept of agency (Steenbeek \& Van Geert, 2007; Van Geert, 2014). The reason is that the concept of inter-action logically entails the concept of action, and agency can be defined as the property of individuals or organisms to act. Another way of putting this is, the participants in the interaction must be conceived of as agents, and their behavior over time must be driven by the principles of agency (Steenbeek \& Van Geert, 2007, 2013; Mercer, 2011; Raeff, 2017). These agency principles are that the participant is an autonomous person, whose behavior is driven by his concerns, interests or goals, who is equipped with the tools to realize those concerns, interests or goals (from skills to material tools), who can perceive and evaluate the current context in terms of those concerns, interests and goals, and who can use these behavioral tools to achieve his concerns in relation to his perception and evaluation of the context (and the context 
is usually defined by what another agent with whom the first agent is interacting, is doing). These concerns, interests, goals, skills, perceptions and evaluations are properties that emerge out of the current context (Perdikis, Huys, \& Jirsa, 2011). For more detailed descriptions of this agency model, in the context of interaction between children and student-teacher interaction, we refer to Steenbeek and Van Geert $(2007,2008)$.
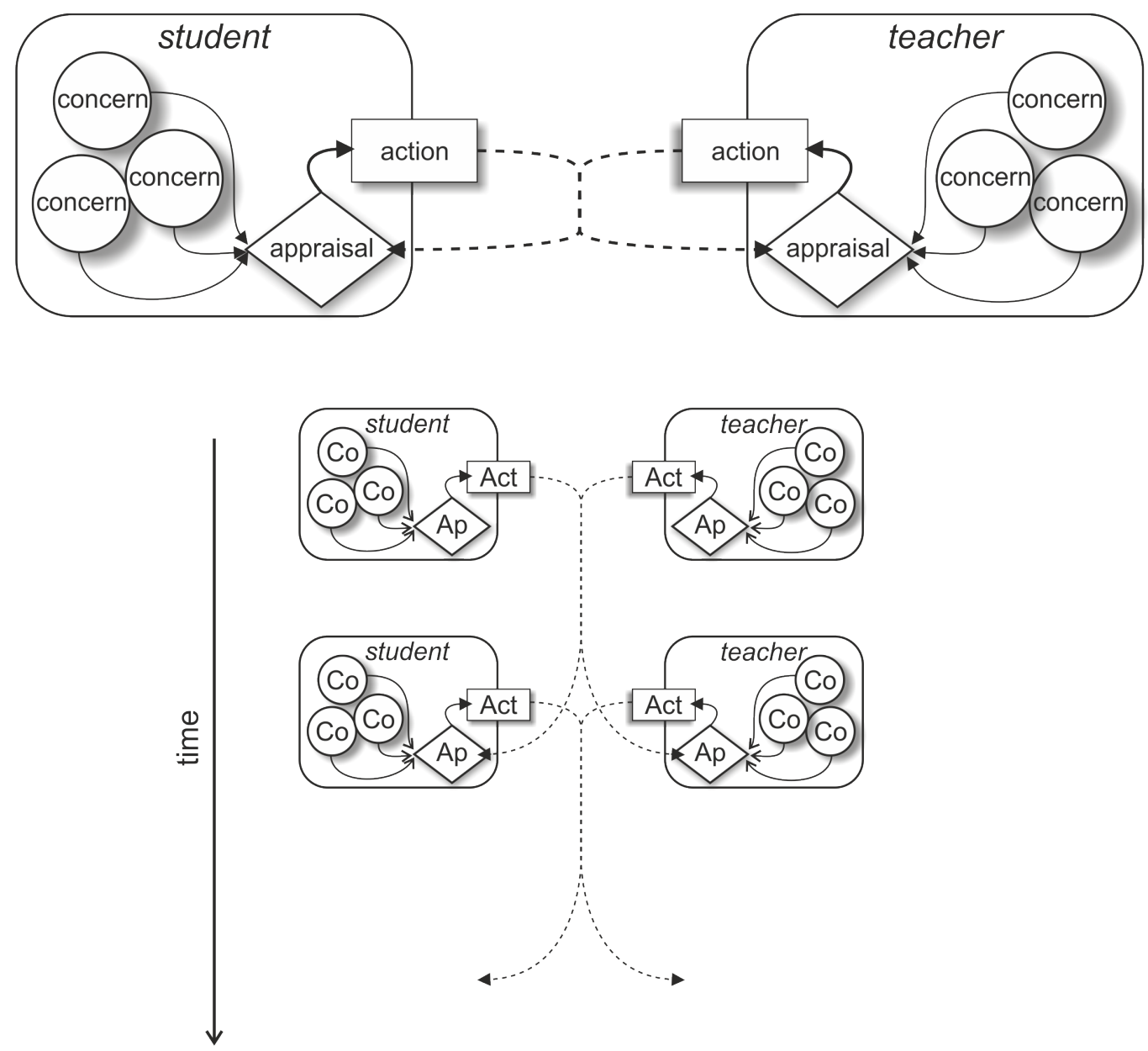

Figure 1. The intertwined and iterative nature of the interaction process, as depicted in the agent model of student-teacher interaction (source: Steenbeek \& van Geert, 2013)

Education research often relies on self-determination theory (Deci \& Ryan, 2000) about three major human concerns, namely the desire for autonomy, for relatedness and for competence. These concerns may help explain why in specific interaction contexts, specific concerns and goals arise, for instance a child's momentary strong desire to solve a problem without help (high autonomy) in order to please the teacher (high relatedness), or a child's continuous reliance on the teacher's help (high relatedness, low autonomy and low competence; Steenbeek \& Van Geert, 2013). 


\section{The State Space as a Perspective on Teacher-Student Interaction Dynamics}

The search for a system's evolution rules - for instance the agency principles that describe how what currently happens between a teacher and student evolves into what happens between this teacher and the student a few seconds later - depends on what we consider important or essential for this teacher-student system. All sorts of things happen all the time, but if we look at the interaction between a teacher and a student from an educational perspective, we will have to reduce the properties to those that, in our view, actually matter. For instance, in the dynamic model of a dyadic interaction that we describe here, the process has been conceptually reduced to the participants directing their action either towards the other person or towards their own action (self-versus other-directedness). These two states may switch over the time course of seconds to minutes. With two participants, we obtain four possible states of the system, and two combinations of those states produce typical attractor states of interaction, namely working together (e.g. the teacher directing his action towards the student and student directing his action towards the teacher) and working alone (both teacher and student directing their attention towards their own activities i.e. not interfering with each other). The set of possible states of the system (four in this particular case) is the system's state space This state space can also be constructed with continuous variables, for instance the variable level of engagement in the educational activity and the variable level of openness of the teacher's questions. The reduction of a complex system to a simple state space should not be interpreted as a reduction in the literal sense, but should again be seen as the choice of a particular perspective on the complex system, that is, a highly reduced description of what the system does in terms of indicator variables and which is used to see and understand the underlying dynamics ${ }^{1}$.

\section{Specifying the Timescale of Interaction Processes}

Interaction dynamics governed by agency principles occur on a variety of timescales. In our work on dyadic play and teacher-student interactions, we have primarily applied those dynamics to the timescale of seconds and minutes, in order to model interaction processes during a short play session or an interaction session as part of the lesson. In principle, such interaction processes can be combined into chains, for instance covering an entire lesson, or a sequence of such lessons. This combination of interactions requires that we formulate rules for dynamically connecting these events on that timescale, specifying, for instance, how the next lesson is determined by the preceding one(s). The dynamics on this macrolevel (as opposed to the microlevel of a single interaction) level is typically governed by processes of learning, formation of expectations, building up and improving skills, and so forth.

\footnotetext{
${ }^{1}$ There is a certain conceptual similarity here with the famous Ruelle-Takens embedding theorem, which has inspired work on Recurrence Quantification Analysis of timeseries, which provides techniques for reconstructing the underlying attractors of the system; for applications to behavioral and educational interactions see Cox et al.
} 


\section{Illustrating the Principles of Interaction with Simulations}

In order to illustrate the principles and properties discussed in the above sections, we present results from a simulation of collaborative play in gender-uniform dyads, which was part of a study of gender differences in collaborative play (Steenbeek, van der Aalsvoort \& Van Geert, 2014). As described earlier, the interaction process was looked at from a very simple perspective, namely whether an action of a participant was either aimed at the other participant or aimed at the participants own activity (other-versus self-directed action). If both participants show an iterative sequence of other-directed actions, the process takes the form of interaction, and if not, the process is one of solitary activity (acting alone). Asymmetrical combinations (e.g. other-directed in one participant self-directed in another) amount to attempts to or initiations of interaction sequences, or to end a particular interaction sequence.
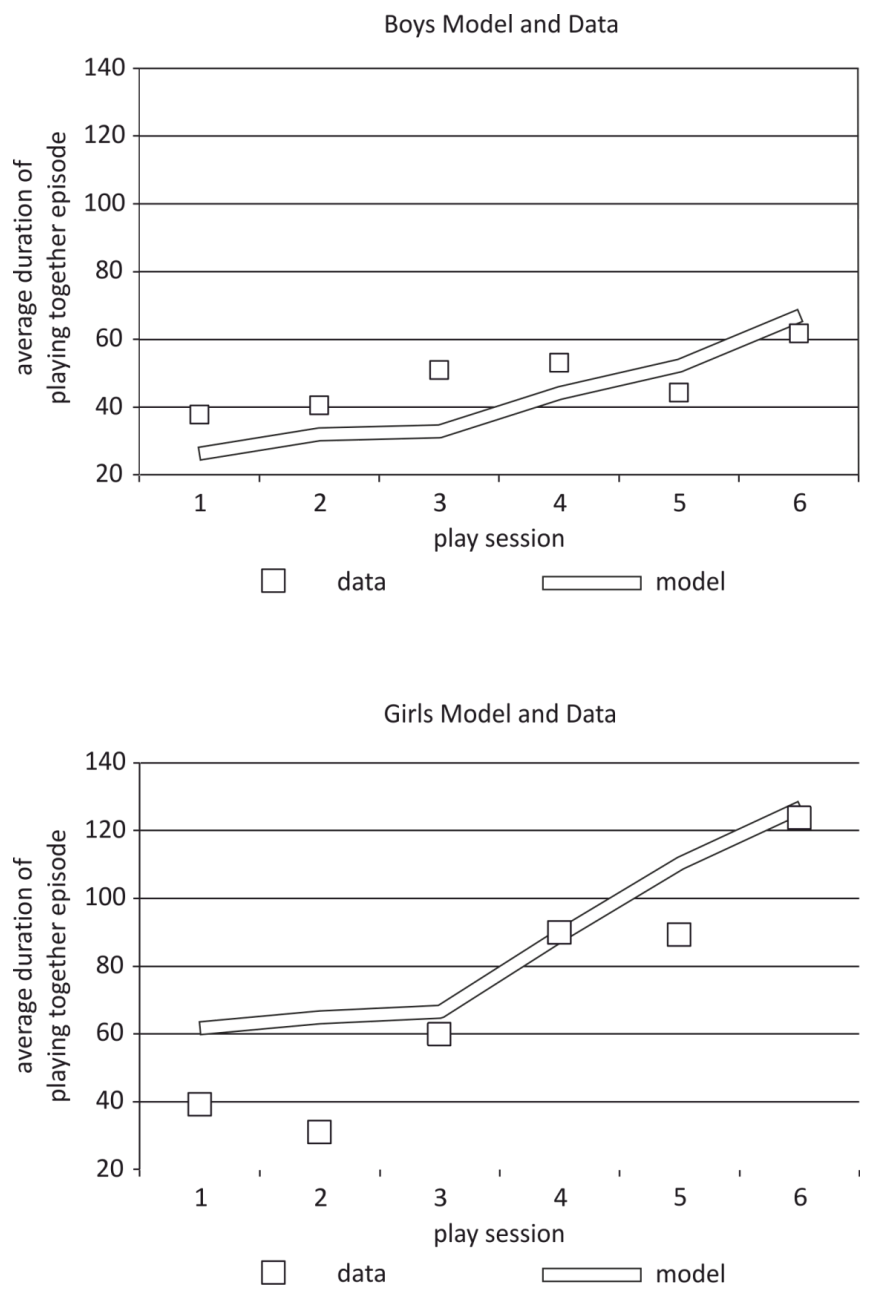

Figure 2. Comparison of simulation data and empirical data play interaction of boys-dyads and girls-dyads (source: Steenbeek, van der Aalsvoort, van Geert, 2014)

The simulation model was based on the conceptual agency model described above, and resulted in simulated time series covering a duration of 10 to 20 minutes, which is the typical duration of 
the observed collaborative play session. The simulation results showed interesting statistical similarities with the empirical data in terms of the typical duration of episodes of interaction in girls versus boys, and changes therein over the course of six intervention sessions (see figure 2). In order to simulate a sequence of such collaborative play sessions with the same children, we postulated that the interaction parameters resulting in a positively evaluated play interaction in a preceding session would affect the interaction parameters of the next play session. Simulation of six consecutive play sessions in boys versus girls dyads resulted in a good prediction of the empirical data.

The majority of the model predictions regarding changes over the course of six sessions were consistent with the data. That is, the average duration and the maximum duration of contact-episodes increased both in boys-dyads and girls-dyads, but differences occurred in the strength of the increase (see figure 2). Contrary to expectation, the number of contact-episodes decreased both in boys-dyads and in girls-dyads. That is, on the basis of simple rules ((self-versus other-directedness), interaction dynamics could be simulated and validated with empirical data.

This model can be used to simulate interaction processes in other educational and developmental contexts. For instance, a conceptually similar model was used to simulate sequences of interaction between a teacher and a student in the context of special education, where such individual teacher-student interaction episodes are more common than in regular education (Steenbeek, Jansen \& Van Geert, 2012; Steenbeek \& Van Geert, 2013). The agent model produced typical sequences of the student working alone on his assignment, and working together with the teacher (Steenbeek \& Van Geert, 2013). Based on the principles of the agent model used to simulate play interaction in young children, Schuhmacher, Ballato \& Van Geert (2014) built a model simulating empirical long-term process data on the formation of friendship groups in adolescents, in relation with the adolescents' initiation and imitation of socially positive versus negative habits, e.g. spending time on school assignments versus use of alcohol and soft drugs. The simulation model predicted the empirically observed process of group formation, including the typical size of the friendship groups and the processes of assimilation and imitation of prosocial and risk behaviors as described in the literature.

\section{An Empirical Approach to Studying Teaching-Learning Processes from a Complex Dynamic Systems Point of View}

The case study, which we shall briefly discuss by way of illustration of the complex dynamic systems approach to teaching-learning, focuses on micro-and macro-genetic processes occurring during science lessons in the upper level of the primary school (see also transcript; p. 3). The overarching aim of the empirical study was to evaluate the effectiveness of a teacher intervention to improve the teacher's pedagogical skills during science lessons, and indirectly also aimed at improving the level of scientific reasoning and engagement and enthusiasm in the students. The intervention took the form of video feedback coaching over the course of eight science lessons. The Video Feedback Coaching for upper grade teachers targeted teacher's pedagogical skills such as their use empirical cycle, scaffolding, and use of questions that elicit students' scientific understanding. However, rather than studying the change in teacher's 
practice in isolation or just focusing on student outcomes, these studies took the complex dynamic system view on teaching-learning processes, implying that individual and contextual factors continuously interact during students' learning and change over time. Although the complexity of educational interactions is increasingly recognized on a theoretical level, it is rarely the focus in the assessment of educational intervention. In these studies, we focused on real-time teacher-students interaction as an important unit of analysis. A complex dynamic systems approach (by means of state space grid analysis, time-serial analysis and cluster analysis) provided evidence of the actual, concrete way in which the intervention attained its effectiveness and showed insight in the change of those processes over the course of the intervention. We argued that if the intervention needs to be improved, or if the intervention needs to be disseminated, knowledge of the actual, concrete way in which it works on the level of real-time daily practice is vital (because that is the kind of information that is available to the teachers). Variable cluster analysis and Hierarchical cluster (HCA) analyses was used as means to get a grip on the coherence pattern on the micro level and changes over macrolevel at the same time. A first question was: Is there coherence in the qualitative properties of openness and engagement? The second question was: Is there coherence over time-points?

A variable cluster analysis allowed to capture the structure of the data independent of time; i.e. all data were taken together in order to examine which levels of openness and engagement cohere (see table 1). The variable cluster analysis yielded three clusters of variables (Table 1). The first variable cluster correlated highly with the observational variable 'teacher-centered question', and is labelled as such. This means that this cluster shows a high degree of teacher-centered behavior. The second variable cluster correlated positively with 'instruction' and 'active away behavior', and negatively with 'interest', and was therefore labelled 'closed and disengaged'. This indicates that within this cluster 'instruction' and 'active away behavior' are most apparent, and 'interest' is rarely found in this cluster. The third variable cluster is labelled as 'open and engaged', because it correlated positively with 'student-centered question' and 'enthusiasm', and negatively with 'information' and 'resignation'. Interestingly, overall low teacher openness often concurs with low student engagement, while high teacher openness behavior often coincides with high student engagement; i.e., the levels can be summarized in behaviors that seem to hinder or benefit the learning process. In terms of educational quality the third dimension (variable cluster 3 ) seems most beneficial for learning because engaged student behavior and open teacher behavior co-occur.

The change in the relation between variables over time was examined using a hierarchical cluster analysis (HCA). The hierarchical cluster analysis gives insight in the change in the relation between variables over time, -specific concerning the occurrence of the variable clusters-, and yielded three clusters of measurement points over time, which are shown in figure 3 and table 2. Table 2 specifies which dimensions are dominant in each cluster: high positive testvalues correspond with cluster properties with higher than average values, and negative testvalues refer to cluster properties that are lower than average. The optimal cluster, for instance, is characterized by high values for the Open \& Engaged properties, and low values for the Closed and Disengaged properties. Figure 3 shows that at the beginning of the intervention (PreM1) the interaction is dominated positively by 'teacher centered', which means that this cluster of time points (cluster 1 - teacher centered) shows a high degree of teacher-centered 
behavior. In addition, this cluster is dominated negatively by 'open and engaged'. This indicates that within this cluster the amount of open and engaged behavior is far less than average. At PreM2 a different cluster (cluster 2 - non optimal) is found in which 'closed and disengaged' behavior dominates positively. From VFC1 (at the start of the intervention) onward there is a change in clusters. Cluster 2 is alternated with cluster 3 (optimal), often halfway the lesson. At PostM (follow-up approximately eight weeks after the intervention) only cluster 3 (dominated positively by 'open and engaged' and negatively by 'closed and disengaged') is found. Overall, this alternation of clusters indicates that there is a change from low teacher openness in combination with low student engagement towards high teacher openness which coheres with high student engagement.

Table 1. Correlations of variable clustering

\begin{tabular}{lccc}
\hline \multicolumn{1}{c}{ Variables } & $\begin{array}{c}\text { Var Cluster 1 } \\
\text { Teacher centered }\end{array}$ & $\begin{array}{c}\text { Var Cluster 2 } \\
\text { Closed and } \\
\text { disengaged }\end{array}$ & $\begin{array}{c}\text { Var Cluster 3 } \\
\text { Open and engaged }\end{array}$ \\
\hline Teacher & -.1515 & & -.1585 \\
\hline Instruction & .2035 & .7044 & -.7709 \\
Information & 1 & .286 & -.1813 \\
Teacher centered & .0147 & -.2318 & .7797 \\
Student centered & .0181 & -.231 & .4845 \\
Encouragement & & -.0974 & \\
Student & -.2847 & & -.1618 \\
Active away & .0419 & .7452 & -.6614 \\
Boredom & .3432 & .241 & -.7753 \\
Resignation & -.1231 & .1576 & .4671 \\
Frustration & .1087 & .0049 & .2523 \\
Interest & -.1362 & -.8501 & .7489 \\
Enthusiasm & -.1232 & \\
\hline
\end{tabular}

Please Note: Marked cells represent main contributing variables for each variable cluster.

From VFC1 to VFC4 (intervention) it appears that 'open and engaged' interaction is most apparent at the beginning of each lesson, while in the second part of the lesson the interaction seems to return to a state of 'closed and disengaged' interaction; which was a common interaction pattern for this class (based on the premeasures). Over the course of the VFCt, cluster 3 becomes increasingly dominant as a recurring state of interaction, and seems to have stabilized at post-measures.

\section{Conclusion and Discussion}

In this article, we provided theoretical justification for and empirical illustrations of a view of and learning as a process of interaction, taking place in a complex dynamic system. W e defined teaching-learning processes as iterative sequences of intertwined events, producing nonlinearity, self-organization, emergence and attractors. Teaching-learning processes constitute layered systems, with embedded layers of organization and embedded timescales. These layers 


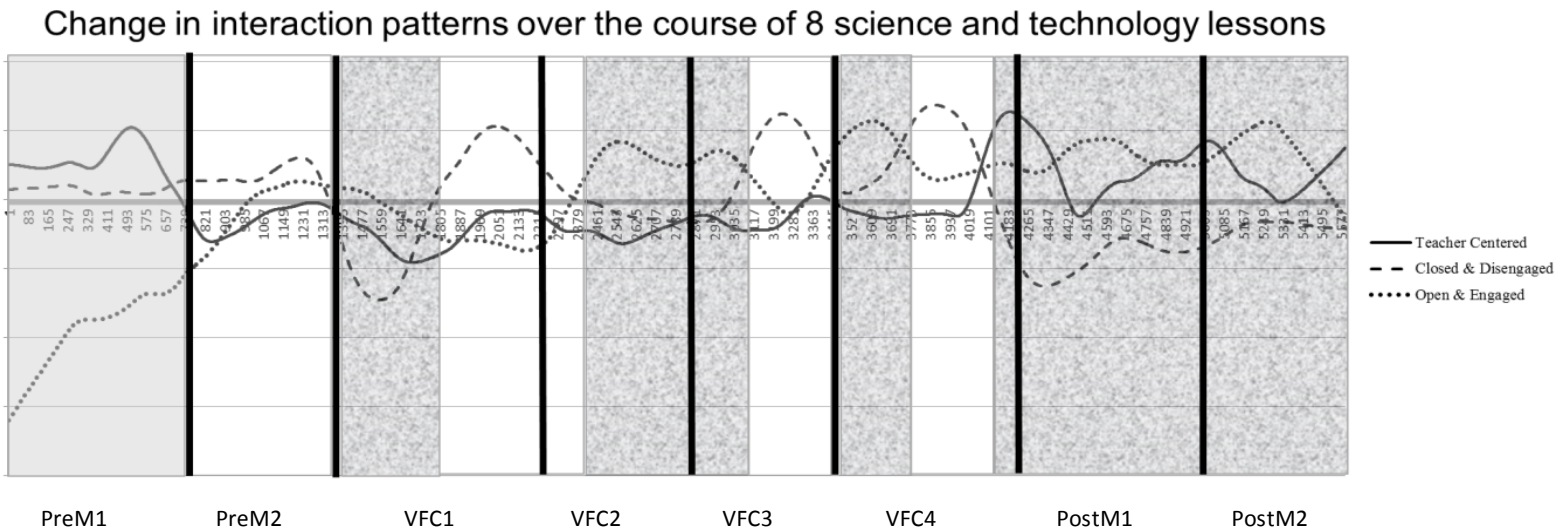

Figure 3. HCA clusters at varying measurement points over time in which the results of the variable clustering are plotted. The black lines mark the end/beginning of a new lesson. Each grayscale represent the time points' different clusters

Table 2. Descriptions of HCA clusters

\begin{tabular}{|c|c|c|c|c|c|}
\hline $\begin{array}{l}\text { Cluster } 1 \text { (gray) } \\
\text { Teacher centered }\end{array}$ & \multicolumn{3}{|c|}{$\begin{array}{c}\text { Cluster } 2 \text { (white) } \\
\text { Non optimal }\end{array}$} & \multicolumn{2}{|c|}{$\begin{array}{c}\text { Cluster } 3 \text { (scattered) } \\
\text { Optimal }\end{array}$} \\
\hline 740 data points & $(13.2 \%)$ & $\begin{array}{l}1997 \text { data } \\
\text { points }\end{array}$ & $(35.7 \%)$ & $\begin{array}{l}2854 \text { data } \\
\text { points }\end{array}$ & $(51.0 \%)$ \\
\hline Variable cluster & $\begin{array}{c}\text { Test } \\
\text { value }\end{array}$ & $\begin{array}{c}\text { Variable } \\
\text { cluster }\end{array}$ & Test value & $\begin{array}{l}\text { Variable } \\
\text { cluster }\end{array}$ & Test value \\
\hline Teacher Centered & 32.79 & $\begin{array}{c}\text { Closed \& } \\
\text { Disengaged }\end{array}$ & 54.65 & $\begin{array}{l}\text { Open \& } \\
\text { Engaged }\end{array}$ & 48.3 \\
\hline $\begin{array}{c}\text { Closed \& } \\
\text { Disengaged }\end{array}$ & 6.4 & $\begin{array}{l}\text { Open \& } \\
\text { Engaged }\end{array}$ & -7.51 & $\begin{array}{l}\text { Teacher } \\
\text { Centered }\end{array}$ & 9.03 \\
\hline Open \& Engaged & -60.63 & $\begin{array}{l}\text { Teacher } \\
\text { Centered }\end{array}$ & -32.61 & $\begin{array}{c}\text { Closed \& } \\
\text { Disengaged }\end{array}$ & -56.72 \\
\hline
\end{tabular}

are coupled, i.e. they interact with one another. Finally, we argued that the dynamics of a teaching-learning system taking place on the layer of organization of interactions between individuals, and on the short-term timescale of interaction between persons, can best be described by means of agency dynamics.

If the properties described in the first section of this article are characteristic of processes, then processes should be studied in such a way that these characteristic properties can indeed be empirically demonstrated (verified or falsified). This means that in order to study a process, one needs to make a great number of observations of the process itself, and one should do so on a variety of timescales (microgenetic to macrogenetic). Given the conditional, iterative connections between the process events over the course of time, a process can only be studied if those conditional iterative connections are actually sampled in the temporal order in which they 
occur. The latter means that in order to obtain an understanding of a particular process, one should begin with collecting a great number of observations of one particular process, e.g. in a particular class and during a particular lesson, and then of another one, and still another one, in order to check the findings achieved in the study of one process with the findings from another process. If there are logistic limitations to the number of process studies one can simultaneously carry out, it is recommendable to analyze each process separately, and then compare the results in order to come to more general conclusions about the underlying process dynamics. However, it is not known in advance if any such more general conclusions regarding similar dynamic principles underlying the wide variety of processes can indeed be drawn. It is very well possible that processes follow very idiosyncratic pathways, with very few similarities with other research processes, except maybe for the most general principles. The latter conclusion, if warranted, would serve as a general conclusion about process dynamics in the field of learning and teaching, namely that they are highly variable and highly idiosyncratic. Comparable studies in the field of early development and clinical psychology and clinical interventions increasingly demonstrate that the underlying processes are indeed highly idiosyncratic, (e.g. Van Dijk \& Van Geert, 2015; Toonen et al., 2016; Polman et al., 2011) and that the process models based on group data (i.e. on inter-individual variability) do not describe the actual processes that occur in individual clients (i.e. that the individual process is not a mere random variation of an underlying common trajectory).

For teaching practice the implications are twofold. First, it means that teaching-learning processes in the classroom can be considered as being highly idiosyncratic and variable, which when teachers are becoming aware of that, can incorporate this insight into their actions in the classroom. For instance, it might help them appreciate short term as well as long term variability as important and probably also necessary features of any successful process of intertwined learning and teaching. It might also help teachers focus on the micro-dynamics of the teaching-learning process, i.e., on what happens here-and-now, as an alternative to the rigid following of curriculum protocols and fixed educational methods. In addition, it may also have an impact on their pedagogical content knowledge, and can potentially diminish the possible stress they may feel with regard to the necessity to having students on a certain learning track on a particular time, during a school year. Finally, it gives room for both teachers and students to follow their own path more with regard to what they are motivated for to study, and in what order and way they study (parts of) the curriculum.

The typical research project, for instance carried out in the context of a research grant or a PhD project, should reckon with serious logistic limitations in terms of the amount of observations and researcher time. Serious process studies will in practice mostly be limited to one or just a few cases (compare this with the typical group based study, in which the number of cases might easily run into the hundreds, and the number of process observations is greatly limited, if any process observations can be made at all). If that is so, empirical process research will in itself amount to an iterative process, with one process study forming the context against which the next process study is done and evaluated. Process research will usually start with single case studies, which, if they are published, can form the starting point for further process research done along the same lines. Such a single case (or few cases) does not claim universality, or neither does it claim that all other cases will be similar. The objection often heard against 
single case studies is that they do not generalize, and should therefore be avoided. However, this objection is similar to saying that the first step in a journey is not the entire journey, and thus that the available resources should not be invested in taking a first step, but should only be invested in making the entire journey. But journeys will never be made if no resources are invested in taking the first step.

\section{References}

Bentley, M.L. (1995). Making the most of the teachable moment: Carpe diem. Science Activities, 32(3), 23-27. Retrieved from http://eric.ed.gov/

Deci, E., \& Ryan, R. (2000). The 'what' and the 'why' of goal pursuits: Human needs and the self-determination of behavior. Psychological Inquiry, 11, 227-268.

DePaepe, de Corte, \& Verschaffel, 2006;

Ensing, A., Van der Aalsvoort, G. M., Van Geert, P. \& Voet, S. (2014). Learning potential is related to the dynamics of scaffolding: An empirical illustration of the scaffolding dynamics of 5-year-olds and their teacher. Journal of Cognitive Education and Psychology, 13(3), 375-391

Fogel, A. (2009). What is a transaction? In A. Sameroff (Ed.), The transactional model of development: How children and contexts shape each other (pp. 271-280). Washington, DC, US: American Psychological Association.

Fischer, K.W. (1980). A theory of cognitive development: The control and construction of hierarchies of skills. Psychological Review, 87, 477-531. doi:10.1037/0033-295X.87.6.477

Hyun, E., \& Marshall, J.D. (2003). Teachable-moment-oriented curriculum practice in early childhood education. Journal of Curriculum Studies, 35(1), 111-127. doi: 10.1080/00220270210125583

Meindertsma, H.B., Van Dijk, M.W.G., Steenbeek, H.W., \& Van Geert, P.L.C. (2012). Application of skill theory to compare scientific reasoning of young children in different tasks. Netherlands Journal of Psychology, 67, 9-19. Retrieved from http://www.springer.com/medicine/journal/12472

Mercer, S. (2011). Understanding learner agency as a complex dynamic system. System, 39(4), 427-436.Molenaar, P. C. (2004). A manifesto on psychology as idiographic science: Bringing the person back into scientific psychology, this time forever. Measurement, 2(4), 201-218.

Molenaar, P. C. (2004). A manifesto on psychology as idiographic science: Bringing the person back into scientific psychology, this time forever. Measurement, 2(4), 201-218. Molenaar, P. C., \& Campbell, C. G. (2009). The new person-specific paradigm in psychology. Current Directions in Psychological Science, 18(2), 112-117.

Perdikis, D., Huys, R., \& Jirsa, V. (2011). Complex processes from dynamical architectures with time-scale hierarchy. PLoS One, 6(2), e16

Polman, A., Bouman, T. K., van Geert, P. C., de Jong, P. J., \& den Boer, J. A. (2011). Dysfunctional beliefs in the process of change of cognitive treatment in obsessive compulsive checkers. Clinical Psychology \& Psychotherapy, 18(3), 256-273.

Raeff, C. (2017). Going where the action is to conceptualize the person. New Ideas in Psychology, 44, 7-13.

Schuhmacher, N. Ballato, L \& Van Geert, P. (2014). Using an agent- based model to simulate the development of risk behaviors during adolescence. Journal of Artificial Societies and Social Simulation, 17 (3), 1; $<$ http://jasss.soc.surrey.ac.uk/17/3/1.html>

Sorsana, C. (2008). Introduction: Developmental co-construction of cognition. European Journal of Developmental Psychology, 5(5), 537-543. doi: 10.1080/13546800701851179

Steenbeek, H., Jansen, L., \& van Geert, P. (2012). Scaffolding dynamics and the emergence of problematic learning trajectories. Learning and Individual Differences, 22(1), 64-75.

Steenbeek, H., van der Aalsvoort, D., \& van Geert, P. (2014). Collaborative play in young children as a complex dynamic system: Revealing gender related differences. Nonlinear Dynamics, Psychology, and Life Sciences, 18(3), 251-276. 
Steenbeek. H. \& Van Geert, P. (2007). A Dynamic Systems Approach to Dyadic Interaction in Children: Emotional Expression, Action, Dyadic Play, and Sociometric Status. Developmental Review, 27 (1), 1-40.

Steenbeek. H. \& Van Geert, P. (2008). The Empirical Validation Of A Dynamic Systems Model Of Interaction; Do Children Of Different Sociometric Statuses Differ In Their Dyadic Play Interactions? Developmental Science, 11(2), 253-281

Steenbeek, H., \& van Geert, P. (2013). The Emergence of Learning-Teaching Trajectories in Education: a Complex Dynamic Systems Approach. Nonlinear Dynamics, Psychology, and Life Sciences, 17, 233-267.

Toonen, R. B., Wardenaar, K. J., Booij, S. H.., Bos, E. H., \& de Jonge, P. (2016), Using local linear models to capture dynamic interactions between cortisol and negative affect. Journal for Person-Oriented Research, 2(3), 142-154. DOI:10.17505/jpor.2016.14.

Van der Steen, S., Steenbeek, H.W., Van Dijk, M.W.G., \& Van Geert, P.L.C. (2014). A process approach to children's understanding of scientific concepts: A longitudinal case study. Learning and Individual Differences, 30, 84-91. doi:10.1016/j.lindif.2013.12.004

Van Dijk, M. \& van Geert, P. (2015). The nature and meaning of intraindividual variability in development in the early life span. In Diehl, M., Hooker, K. \& Sliwinski, M. J. (eds.). Handbook of intraindividual variability across the life span. Routledge, Taylor and Francis group, p. 37-58

Van Geert, P. (2014). Group versus individual data in a dynamic systems approach to development. Enfance, 2014 (3), 283-312

Van Vondel, S., Steenbeek, H.W., Van Dijk, M.W.G., \& Van Geert, P.L.C. (2016). 'Looking at' Educational interventions: Surplus value of a complex dynamic systems approach to study the effectiveness of a science and technology educational intervention. In M. Koopmans, \& D. Stamovlasis (Eds.), Complex dynamical systems in education: Concepts, methods and applications (pp. 203-232). New York: Springer. doi: 10.1007/978-3-319-27577-2

Van Vondel, S., Steenbeek, H.W., Van Dijk, M.W.G., \& Van Geert, P.L.C. (2017a). The effects of Video Feedback Coaching for teachers on primary students' scientific knowledge. Research in Science Education. doi: 10.1007/s11165-016-9569-z

Van Vondel, S., Steenbeek, H.W., Van Dijk, M.W.G., \& Van Geert, P.L.C. (2017b). Ask Don't Tell: A complex dynamic systems approach to improving science education by focusing on the co-construction of scientific understanding. Teaching and Teacher Education. doi: 10.1016/j.tate.2016.12.012

Vosniadou, S. (2007). Conceptual Change and Education. Human Development, 50(1), 47-54.

Wetzels, A., Steenbeek, H., \& van Geert, P. (2016). A complexity approach to investigating the effectiveness of an intervention for lower grade teachers on teaching science. Complicity: An International Journal of Complexity and Education, 13(1), 81-104.

\section{About the Authors}

Henderien Steenbeek, PhD works as an associate professor at the department of Developmental Psychology and as a professor at Teacher College at the University of Applied Studies in Groningen. Her research themes are: children's learning processes in primary education (with a focus on children with special needs, and excellent performing children), and the dynamics of children's play. Correspondence: $\underline{\text { h.w.steenbeek@rug.nl }}$

Sabine van Vondel is a Ph.D. candidate in developmental psychology at the University of Groningen. The focus of her thesis is studying the effects of a Video Feedback Coaching intervention for teachers on teacher-student interactions during science and technology education. Her research interests focus on the interface of educational science and developmental psychology, more specifically on teaching-learning processes that support (or hinder) student's learning in elementary education. E-mail: s.van.vondel@rug.nl

Paul van Geert (1950) is professor emeritus of Developmental Psychology and currently Honorary Professor of Complex Dynamic Systems in Education and Development at the University of Groningen (the Netherlands). He has had a pioneering role in the application of dynamic systems theory to a broad range of developmental and educational areas. His main aim is to better understand the nature of the mechanisms that drive and shape 
developmental and educational processes in individuals as they interact with their actively explored and transformed environments. For his research and an overview of his artwork, see www.paulvangeert.nl

(C) Copyright 2017. The authors, HENDERIEN STEENBEEK, SABINE VAN VONDEL, \& PAUL VAN GEERT, assign to the University of Alberta and other educational and non-profit institutions a non-exclusive license to use this document for personal use and in courses of instruction provided that the article is used in full and this copyright statement is reproduced. The authors also grant a non-exclusive license to the University of Alberta to publish this document in full on the World Wide Web, and for the document to be published on mirrors on the World Wide Web. Any other usage is prohibited without the express permission of the authors. 